\title{
Prostanoid receptor EPI and Cox-2 in injured human nerves and a rat model of nerve injury: a time-course study
} Pascal F Durrenberger ${ }^{1}$, Paul Facer ${ }^{1}$, Maria A Casula ${ }^{1}$, Yiangos Yiangou ${ }^{1}$, Roy A Gray², Iain P Chessell ${ }^{2}$, Nicola C Day², Sue D Collins ${ }^{2}$, Sharon Bingham², Alex W Wilson ${ }^{2}$, David Elliot ${ }^{3}$, Rolfe Birch ${ }^{4}$ and Praveen Anand*1

Address: ${ }^{1}$ Peripheral Neuropathy Unit, Imperial College London, Area A, Ground Floor, Hammersmith Hospital, London W12 0NN, UK, ${ }^{2}$ Neurology \& GI CEDD, GlaxoSmithKline, Harlow, UK, ${ }^{3}$ St Andrew's Centre, Broomfield Hospital, Chelmsford, UK and ${ }^{4}$ Peripheral Nerve Injury Unit, Royal National Orthopaedic Hospital, Stanmore, UK

Email: Pascal F Durrenberger - p.durrenberger@imperial.ac.uk; Paul Facer - p.facer@imperial.ac.uk; Maria A Casula - m.casula@imperial.ac.uk; Yiangos Yiangou - y.yiangou@imperial.ac.uk; Roy A Gray - Roy.A.Gray@gsk.com; Iain P Chessell - Iain.P.Chessell@gsk.com;

Nicola C Day - Nicola_C_Day@gsk.com; Sue D Collins - S_D_Collins@gsk.com; Sharon Bingham - Sharon_Bingham-1@gsk.com; Alex W Wilson - Alex.W.Wilson@gsk.com; David Elliot - info@david-elliot.co.uk; Rolfe Birch - benita.patel@rnoh.nhs.uk;

Praveen Anand* - p.anand@imperial.ac.uk

* Corresponding author

Published: 04 January 2006

BMC Neurology 2006, 6:1 doi:10.1 186/147/-2377-6-I
Received: 24 May 2005

Accepted: 04 January 2006

This article is available from: http://www.biomedcentral.com/I47I-2377/6/I

(c) 2006 Durrenberger et al; licensee BioMed Central Ltd.

This is an Open Access article distributed under the terms of the Creative Commons Attribution License (http://creativecommons.org/licenses/by/2.0), which permits unrestricted use, distribution, and reproduction in any medium, provided the original work is properly cited.

\begin{abstract}
Background: Recent studies show that inflammatory processes may contribute to neuropathic pain. Cyclooxygenase-2 (Cox2 ) is an inducible enzyme responsible for production of prostanoids, which may sensitise sensory neurones via the EPI receptor. We have recently reported that while macrophages infiltrate injured nerves within days of injury, they express increased Cox2 -immunoreactivity (Cox-2-IR) from 2 to 3 weeks after injury. We have now investigated the time course of EPI and Cox-2 changes in injured human nerves and dorsal root ganglia (DRG), and the chronic constriction nerve injury $(\mathrm{CCl})$ model in the rat.

Methods: Tissue sections were immunostained with specific antibodies to EPI, Cox-2, CD68 (human macrophage marker) or OX42 (rat microglial marker), and neurofilaments (NF), prior to image analysis, from the following: human brachial plexus nerves ( 21 to 196 days post-injury), painful neuromas ( 9 days to 12 years post-injury), avulsion injured DRG, control nerves and DRG, and rat $\mathrm{CCl}$ model tissues. EPI and NF-immunoreactive nerve fibres were quantified by image analysis.

Results: EPI:NF ratio was significantly increased in human brachial plexus nerve fibres, both proximal and distal to injury, in comparison with uninjured nerves. Sensory neurones in injured human DRG showed a significant acute increase of EPI-IR intensity. While there was a rapid increase in EPI-fibres and CD-68 positive macrophages, Cox-2 increase was apparent later, but was persistent in human painful neuromas for years. A similar time-course of changes was found in the rat $\mathrm{CCl}$ model with the above markers, both in the injured nerves and ipsilateral dorsal spinal cord.

Conclusion: Different stages of infiltration and activation of macrophages may be observed in the peripheral and central nervous system following peripheral nerve injury. EPI receptor level increase in sensory neurones, and macrophage infiltration, appears to precede increased Cox-2 expression by macrophages. However, other methods for detecting Cox-2 levels and activity are required. EPI antagonists may show therapeutic effects in acute and chronic neuropathic pain, in addition to inflammatory pain.
\end{abstract}




\section{Background}

Tissue damage induces an inflammatory response including the production of prostaglandins (PGs) such as $\mathrm{PGE}_{2}$, which activate the EP1 receptor expressed by sensory fibres. PGs produced in the spinal cord may also play an important role in the development of hypersensitivity following peripheral nerve injury [1]; PGs generated by Cox2 in the spinal cord have been shown to contribute to the maintenance of hyperalgesia [2].

The enzymes involved in the production of PGs are cyclooxygenases (Cox) of which Cox-1 was at first thought to be the only enzyme present. Subsequently, it was found that Cox activity could be induced by inflammatory cytokines, suggesting the existence of a second isoform. This was confirmed by the isolation of a second cyclooxygenase gene encoding Cox-2 [3]. The classical view that Cox-1 was constitutive and that Cox-2 was exclusively a pro-inflammatory inducible enzyme [4] was challenged since both isoforms are present in different tissues and sites of inflammation, and induced differentially $[5,6]$. Cox-2 protein is upregulated in a number of non-neuronal cell types such as macrophages, human monocytes, synoviocytes, and microglia in CNS inflammation $[7,8]$. Data indicate that Cox-2 is strongly involved in different processes of central nervous modelling and regulated by different signalling pathways. The explicit roles of the constitutive enzyme in the pain and inflammatory processes remains to be fully determined [9]. Evidence that prostanoids could sensitise the peripheral nerve terminals [10] has triggered new research in the Cox enzymes involved in the biosynthesis of PGs to develop inhibitors (Coxibs) of potential therapeutic value.

The contribution of prostanoids such as $\mathrm{PGE}_{2}$ or $\mathrm{PGE}_{2 \alpha}$ in inflammatory processes [11] and in pain modulation has well been defined $[12,13]$ and reviewed [14]. PGE 2 signals via a transmembrane G-protein coupled receptor (EP), of which four types have been identified (EP1-4) [13,15]. EP1 receptor stimulation mediates increases in intracellular calcium ions $\left(\mathrm{Ca}^{2+}\right)$, facilitating neurotransmitter release $[16,17]$. EP1 receptor involvement in pain mechanisms has been described in animal studies [18,19]. EP receptor antagonists have provided evidence of a role for EP receptors in reducing hyperalgesia and allodynia in rodents [20]. Localisation studies have revealed that EP1 mRNA is expressed in rat DRG neurones [21-23]. A recent study demonstrated that $\mathrm{PGE}_{2}$, via the EP1 receptor, contributed to human visceral pain hypersensitivity [24]. The emerging general consensus of animal and human studies identifies the EP1 receptor as a selective target of therapeutic value, of similar analgesic effect as non-steroidal antiinflammatory drugs (NSAIDs), but with fewer potential side effects [18].
Activation of immune-like glial cells such as astrocytes or microglia has been reported in numerous conditions, and may contribute to hyperalgesia, mechanical allodynia or chronic inflammatory pain in animal models. Microglia are phagocytic, cytotoxic and antigen-presenting cells that upon activation are involved in a pattern of cellular responses, including proliferation, recruitment to the site of injury and increased expression of immunomolecules [25]. Glial activation can be induced by substances released from neurones such as PGs, nitric oxide, fractalkine, substance $P$, excitatory amino acids and adenosine 5 'triphosphate (ATP) [26], and in turn, result in the release of numerous inflammatory agents such as cytokines, growth factors, kinins, purines, amines, prostanoids and ions [27]. These inflammatory agents have been shown to activate and/or enhance the sensitivity of primary afferents and spinal cord neurones, and thus glial activation may play a role in nociceptive processing [28-31]. However, some studies report lack of correlation of neuropathic pain behaviour with levels of microglial activation in animal models [32].

The aim of this study was to investigate the time-course of key neuronal-inflammatory interactions in injured human nerves and DRG, and in the CCI rat model. Macrophage/microglia-like cells, Cox-2 and EP1 receptor levels were studied, using immunocytochemistry and Western blotting.

\section{Methods}

Human tissue

Fully informed consent was obtained for all tissues, which were collected with approval of the Local Ethics Committee. Injured human nerve specimens (proximal and distal to site of injury) were obtained during surgery for brachial plexus repair $[\mathrm{n}=11$; acute $(<21$ days $), \mathrm{n}=5,5$ males, age range 20-66 years; chronic ( $>21$ days) $n=6,4$ males and 2 females, age range 24-35 years] and avulsed DRG [n = 11 ; acute $(<21$ days $) \mathrm{n}=5,5$ males, age range $18-39$ years; chronic ( $>21$ days), $\mathrm{n}=6,5$ males and 1 female, age range 21-39 years]. Painful human distal limb neuromas were obtained during surgery $(\mathrm{n}=12 ; 9$ males and 3 females; age range 26-63 years; injury duration from 9 days to 12 years) - the mean pain scores on a visual analogue scale (VAS) were all $>4$ out of 10 at the time of surgery, and patients reported this or a higher level of pain usually continuously since the time of injury. Uninjured control human nerve tissue $(n=9,5$ males and 4 females, age range 39-77 years) was obtained during surgery for limb amputation for non-neurological tumours from patients with no neurological symptoms or signs. Control, post-mortem DRG ( $\mathrm{n}=7,2$ males and 5 females, age range 34-88) were obtained from Netherlands Brain Bank with a post-mortem delay of less than $12 \mathrm{~h}$. Tissues were 
snap frozen in liquid nitrogen and stored at $-70^{\circ} \mathrm{C}$ until use.

\section{Rat tissue}

Adult male Sprague-Dawley rats $(\mathrm{n}=32 ; 200-250 \mathrm{~g})$ were used in this study. CCI animals $(\mathrm{n}=16)$ had the left sciatic nerve loosely ligated with chromic gut sutures to cause a constriction injury. Control, sham-operated animals $(\mathrm{n}=$ 16) underwent identical surgical procedures but without nerve constriction. In brief, under isoflurane anaesthesia, the common left sciatic nerve was exposed at mid thigh level. Four loose ligatures of chromic gut (4.0) were tied loosely around the nerve with a spacing of $1 \mathrm{~mm}$ between each. The wound was then closed and secured with suture clips. The surgical procedure was identical for the shamoperated animals except the sciatic nerve was not ligated. CCI-induced decrease in mechanical paw withdrawal threshold was measured using an algesymeter [33]. To determine threshold, an increasing weight was applied to the dorsal surface of the left and right hindpaw until the rat attempted to withdraw the paw. To study glial activation and Cox- 2 expression, animals were sacrificed on days 4,21 , and $30(\mathrm{n}=4$ in each experimental group and for each time point) and tissues harvested. Left and right sciatic nerve (nerve tissue from 4 days post-operation only was available for this study), and lumbar spinal cord were collected. Tissues were snap frozen in 2-methyl butane cooled in liquid nitrogen and stored at $-70^{\circ} \mathrm{C}$ until use. All procedures involving the use of animals were approved by the UK Home Office and were carried out in accordance with the requirements of the project licence.

\section{Immunocytochemistry}

Tissues were supported in optimum cutting tissue (OCT) medium (Raymond A Lamb Ltd, Eastbourne, UK) to allow best orientation (transverse for spinal cord, longitudinal for nerve). Frozen sections (10 $\mu \mathrm{m}$ thick) were collected onto poly-L-lysine (Sigma, Poole, UK) coated glass slides and post-fixed in freshly prepared $4 \% \mathrm{w} / \mathrm{v}$ paraformaldehyde in $0.15 \mathrm{M}$ phosphate buffered saline (PBS) for $30 \mathrm{~min}$. Endogenous peroxidase was blocked by incubation in industrial methylated spirit (IMS) containing 0.3\% $\mathrm{w} / \mathrm{v}$ hydrogen peroxide. After rehydration, sections were incubated overnight with primary antibody. The primary antibodies for EP1 were polyclonal rabbit anti-human EP1 receptor antibody (1:500, Cayman Chemical, Bingham, UK) and polyclonal rabbit anti mouse EP1 receptor antibody (1:500, Alpha Diagnostic International, San Antonio, Texas, USA), which showed similar results (results shown for Cayman antibody only). Other primary antibodies used included monoclonal anti-Cox-2 antibody (1:250, Transduction Laboratories, Cowley, UK, Clone33), monoclonal mouse anti-CD68 as a well-established marker of human macrophages [34], described in numerous previous publications (1:500, Dako, Ely, UK,
Clone EBM11), mouse anti-rat CD11b antibody as a macrophage/microglial marker in rats (1:1000, Serotec, Kidlington, UK, CloneMRC OX42), a monoclonal mouse antibody to the neurofilament phosphorylated and nonphosphorylated $200 \mathrm{kDa}$ molecular forms (1:50000, Sigma Laboratories, Saint-Louis, MI, USA, Clone N52) and a rabbit polyclonal antiserum antibody cocktail to neurofilaments (1:5000, Affinity Research Products Limited, Exeter, UK). The rat microglial marker (OX42/ $\mathrm{CD} 11 \mathrm{~b})$ previously showed similar levels of expression in $\mathrm{CCI}$ rat tissue as with another microglial marker $\left(\left[{ }^{3} \mathrm{H}\right](\mathrm{R})\right.$ PK11195) [35]. Sites of primary antibody attachment were revealed using nickel-enhanced, avidin-biotin peroxidase (ABC - Vector Laboratories, Peterborough, UK) as formerly described [36]. Sections were counter-stained for nuclei in $0.1 \% \mathrm{w} / \mathrm{v}$ aqueous neutral red, dehydrated and mounted in xylene-based mountant (DPX; BDH/Merck, Poole, UK), prior to photomicrography. Negative controls without primary antibody were incubated with normal rabbit or mouse serum. EP1 peptide antigen from GlaxoSmithKline/Cayman Chemicals was used at $10^{-1}$ to $10^{-6}$ $\mathrm{mg} / \mathrm{ml}$ and pre-incubated with anti-EP1 (Cayman) at $1 /$ 5000 on a control DRG and at 1/2000 on an acute injured DRG. Both control and injured DRG showed reduced staining at high $\left(10^{-1}-10^{-2} \mathrm{mg} / \mathrm{ml}\right)$ concentrations of peptide antigen, compared to sections stained in the presence of antibody alone.

Immunoreactive cells were quantified by computerized image analysis (Seescan Cambridge, UK). Analogue images were captured via video link to an Olympus BX50 microscope and converted into a digital monochrome image by the computer. The grey-shade detection threshold was set at a constant level to allow detection of positive immunostaining and the area of highlighted immunoreactivity was expressed as a \% area of the field scanned. One section per nerve specimen was image-analysed at the stated optimum dilution (this followed a series of 5 sections immunostained with 5 different antibody dilutions). The visual fields were selected at random, avoiding edges of the section. The area was $442 \mu \mathrm{m} \times$ $332.8 \mu \mathrm{m}$. Three to five fields per tissue section were scanned and the mean value was used in subsequent statistical analysis. For DRG, the intensity of immunoreaction of sensory neurones was assessed in blinded fashion by two observers at two dilutions of antibodies and given a mean score (vision inspection scale: $0=$ no immunoreaction; 1 = weak; 2 = medium; 3 = strong). DRG neurones were counted in the entire section (mean 54.58; range 3487) per DRG.

\section{Western blotting}

Brachial plexus nerves from 4 controls and 8 injured patients ( 3 acute and 5 chronic injured) were available for Western blotting. Note that only 3 samples for the acute 

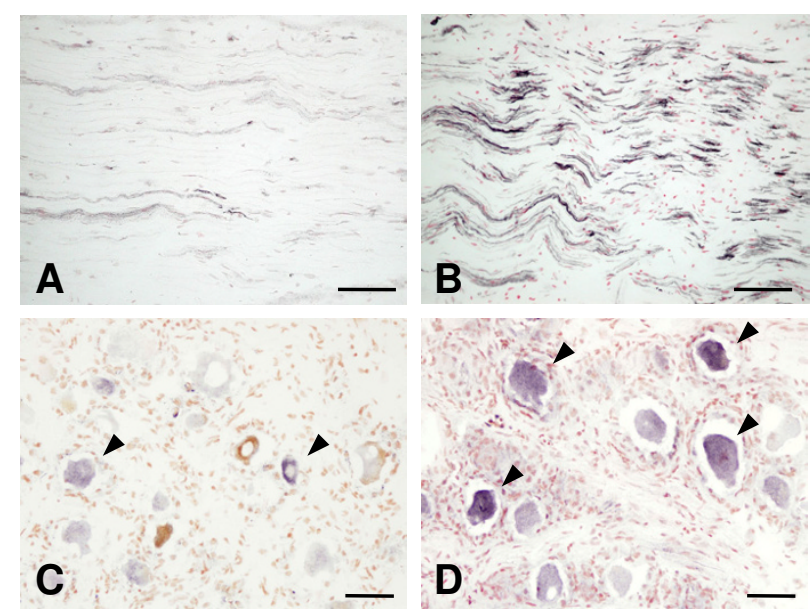

Figure I

EPI immunoreactivity in human injured brachial plexus nerves and avulsed DRG. EPI-IR was observed in nerve fibres in control nerves $(A)$ and appeared more intense in injured nerves (B). EPI-IR was detected mainly in some small/medium diameter neurones (arrowheads) of control (C) and more so in injured human DRG (D). Scale bars $=50$ $\mu \mathrm{m}$.

group were available (10, 15 and 17 days of injury duration) and represent the latter stage of the "acute" phase. Nerve extracts and mouse macrophage control extracts (Transduction Labs, Cowley, UK) were processed for Western blotting as described [37]. Briefly, non-specific antibody binding sites were blocked by incubating the strips in $5 \%(\mathrm{w} / \mathrm{v})$ non-fat dried milk in a solution of PBS containing $0.1 \%(\mathrm{v} / \mathrm{v})$ Tween 20 for $1 \mathrm{~h}$. Primary antibody incubation was $2 \mathrm{~h}$ or overnight in block buffer (Cox-2 at a titre of 1:2000). After washing, sites of attachment of primary antibodies were detected using immunoperoxidase reagents (Vector Laboratories, Peterborough, UK). Immunoreactivity using chemiluminescence was visualised on Hyperfilm film after treatment with Electrophoresis Chemiluminescence (ECL)-plus Western blotting detection system (Amersham Biosciences Ltd, Little Chalfont, UK). Optical density readings of each Hyperfilm were taken using a Digit-X densitometer (X-Ograph Ltd, Tetbury, UK) evenly illuminated on a photography viewer. Background readings were determined by measuring optical density outside the sample lanes. After subtraction of background, the mean of three consecutive readings of protein immunoreactivity at the $70-\mathrm{kDa}$ positions for each sample lane was obtained.

\section{Statistical analysis}

Descriptive statistics were generated using Microsoft Excel 2000 for Windows (Microsoft, Redmond, WA, USA) and GraphPad Prism version 3.00 for Windows (GraphPad

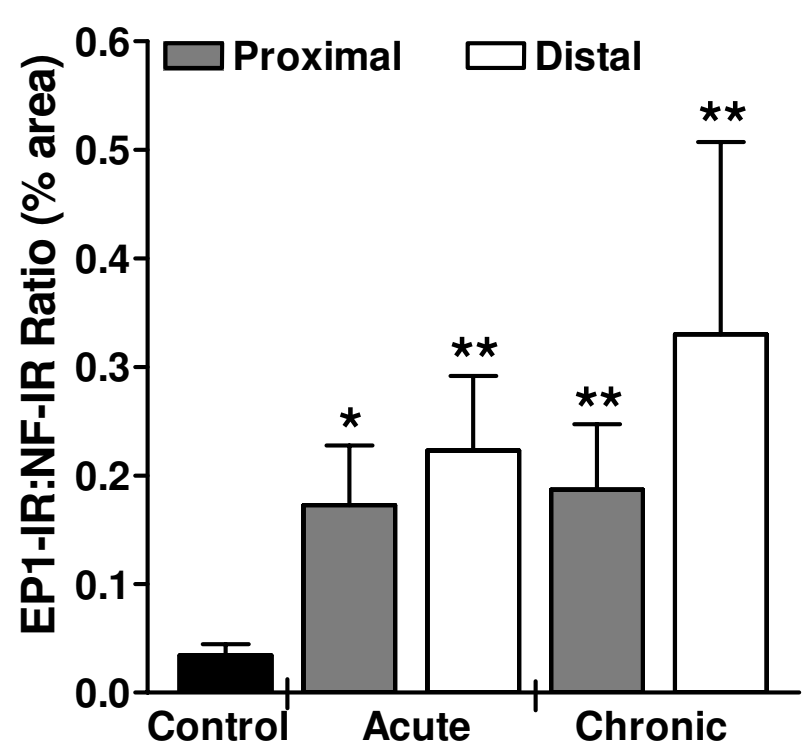

Figure 2

EPI-IR:NF-IR ratio in human proximal and distal injured nerves. Significant increases of EPI-IR:NF-IR ratios were observed in human nerves proximal and distal to injury when compared to uninjured nerves. ${ }^{*} p<0.03$; $* * p<0.01$.

Software, San Diego California, USA). Group differences were assessed using a nonparametric test, the Mann-Whitney U test (one-tailed), in GraphPad Prism. Statistical significance was considered at $\mathrm{P}<0.05$.

\section{Results}

Human brachial plexus nerves and DRG

Both EP1 antibodies showed immunoreactivity in nerve fibres (Figure 1A), which appeared more intense in acute injured nerves (Figure $1 \mathrm{~B}$ ). The results of image analysis are given below. In human DRG, EP1 immunoreactivity (EP1-IR) was detected in small/medium diameter neurones of control (Figure 1C) and injured human DRG (Figure 1D). A significant increase of intensity was observed using the visual inspection scale in DRG sensory neurones after injury in the acute group (surgery delay < 21 days; $3.5 \pm 0.34)$ compared to control DRG $(2.57 \pm$ $0.20, \mathrm{p}=0.02)$. Chronic injured DRG were not significantly different $(2.83 \pm 0.17)$.

EP1 and NF-immunoreactive nerve fibres were quantified by image analysis (\% immunopositive area) in injured and control nerves and expressed as the ratio EP1:NF (Figure 2). EP1-IR:NF-IR ratio was significantly higher in injured acute proximal $(0.17 \pm 0.05 ; \mathrm{n}=5 ; \mathrm{p}<0.03)$ and distal $(0.22 \pm 0.69 ; \mathrm{n}=5 ; \mathrm{p}<0.01)$ and injured chronic proximal $(0.19 \pm 0.06 ; \mathrm{n}=6 ; \mathrm{p}<0.01)$ and distal $(0.33 \pm$ 


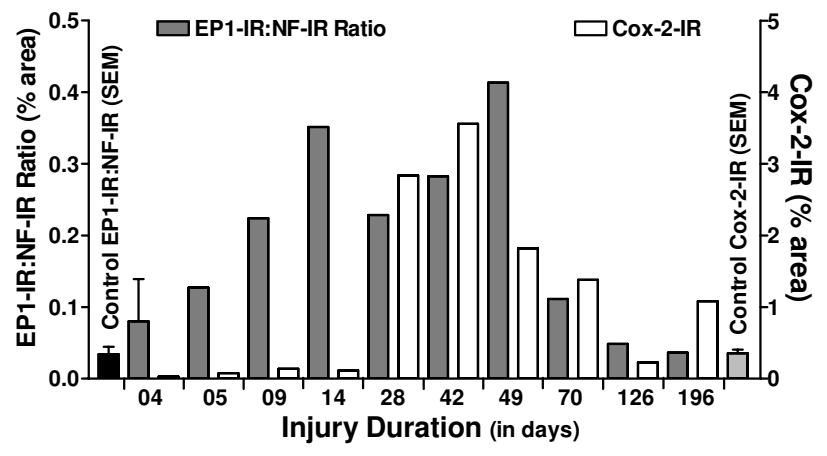

Figure 3

EP I-IR:NF-IR ratio and Cox-2-IR in proximal brachial plexus injured nerves - time course. The time course of EPI-IR:NF-IR ratio and Cox-2-IR showed that EPI preceded Cox-2-IR increased levels.

$0.18 ; \mathrm{n}=6 ; \mathrm{p}<0.01)$ nerves compared to controls $(0.03 \pm$ $0.01 ; \mathrm{n}=5)$.

A time course analysis of EP1-IR:NF-IR ratio and Cox-2-IR in human brachial plexus nerves showed that EP1 expression preceded Cox-2-IR increased levels (Figure 3). Similar results were found with both EP1 markers.

A $70 \mathrm{kDa}$ Cox-2 band was observed in mouse macrophage control and human nerve extracts, which was clearly more prominent in the acute nerves (Figure 4). The optical density of the Cox-2 70kDa band was significantly increased $(\mathrm{p}=0.02)$ in the acute group $(1.41 \pm 0.04, \mathrm{n}=3)$ compared to control nerves $(0.55 \pm 0.09, \mathrm{n}=4)$. No statistical significant difference was detected for the chronic group $(0.61 \pm 0.09, \mathrm{n}=5)$.

\section{Human painful neuromas}

Few, scattered microglial/macrophage-like, Cox-2 immunoreactive cells were found throughout the uninjured human nerve tissue (Figure 5A). Similar cells, but with more abundance were observed in the painful neuromas (Figure 5B). Immunostaining for CD68 showed cells with similar morphology and distribution to Cox-2 in controls (Figure 5C), with an increase in neuromas (Figure 5D.).

Image analysis showed Cox-2-IR (in \% area) to be significantly greater in human neuromas $(0.79 \pm 0.14 ; \mathrm{n}=12 ; \mathrm{p}$ $=0.0022)$ than in controls $(0.32 \pm 0.04 ; \mathrm{n}=13$; Figure 6$)$. A similar increase was found with the macrophage marker CD68. CD68 immunoreactivity (CD68-IR) was significantly increased in human limb neuromas $(8.96 \pm 0.99 ; \mathrm{n}$ $=12 ; \mathrm{p}<0.0001)$ compared to the control group $(0.32 \pm$ $0.04 ; \mathrm{n}=13)$.
A time course analysis of injury duration (time elapsed between the injury and the removal of the neuroma) demonstrated an immediate increase in CD68-IR, which remained above control levels during the entirety of the time course (Figure 7). Cox-2-IR increases, as previously described, were only apparent from 2 to 3 weeks after injury [35], and persistent for years.

Few nerve fibres showed some EP1 immunoreactivity but fibres were too sparse to show significant statistical difference.

\section{$\mathrm{CCl}$ rat model studies}

Unilateral constriction injury to the sciatic nerve resulted in a reduction in paw withdrawal threshold ipsilateral to the nerve injury, usually evident at 9 days and maintained until after 30 days post-operation (in these rats, at 30 days post-operation: CCI, $88.12 \pm 7.04 \mathrm{~g} ; \mathrm{n}=8$, sham $127.5 \pm$ $75.13 \mathrm{~g} ; \mathrm{n}=8$ ). Following behavioural testing on day 04 , 21 and 30, the animals were humanely sacrificed and tissues prepared for immunocytochemistry. Sham operation had no significant effect on paw withdrawal threshold compared to basal levels.

In rat nerve, Cox-2-IR and CD68-IR were found in cells similar to those seen in human nerve tissue as previously described [35]. Few scattered Cox-2 positive cells were seen within the nerve fascicles in sham-operated or control nerves. In CCI nerve, these cells appeared more numerous proximal to the injury site, but this was not statistically significant at 4 days and showed only a trend ( $p$ $=0.057$ ); in our previous study, we have shown a significant increase at 40 days post-surgery [35]. Antibodies to the rat macrophage/activated microglia marker (CD11bOX42) showed few positively stained cells in sham-operated or control nerves (Figure 8), and an abundance of positively stained cells in day 4 post CCI-lesioned nerves $(\mathrm{n}=4,4.58 \pm 0.46)$ compared to sham-operated nerves ( $\mathrm{n}$ $=4,0.26 \pm 0.02 ; \mathrm{p}<0.001$, Figure 9).

In the spinal cord of sham-operated rats at all time points, small, microglial-like Cox-2-immunoreactive cells, with some fine processes, were scattered throughout the grey matter and the white matter (Figure 10A). These cells tended to be less prevalent in the grey matter of CCI rat spinal cords at earlier time points $(4,21$ and 30 days; Figure $10 \mathrm{~B})$. The macrophage/activated microglia marker (CD11b-OX42) showed small, scattered cells of similar morphology to Cox-2 immunoreactive cells, usually with several processes (Figure 10C). These cells appeared to increase in number and intensity in the spinal cord on the side of the nerve lesion, mainly in the superficial dorsal horn (Laminae I-II) and the ventral horn (Laminae IX, Figure 10D). 


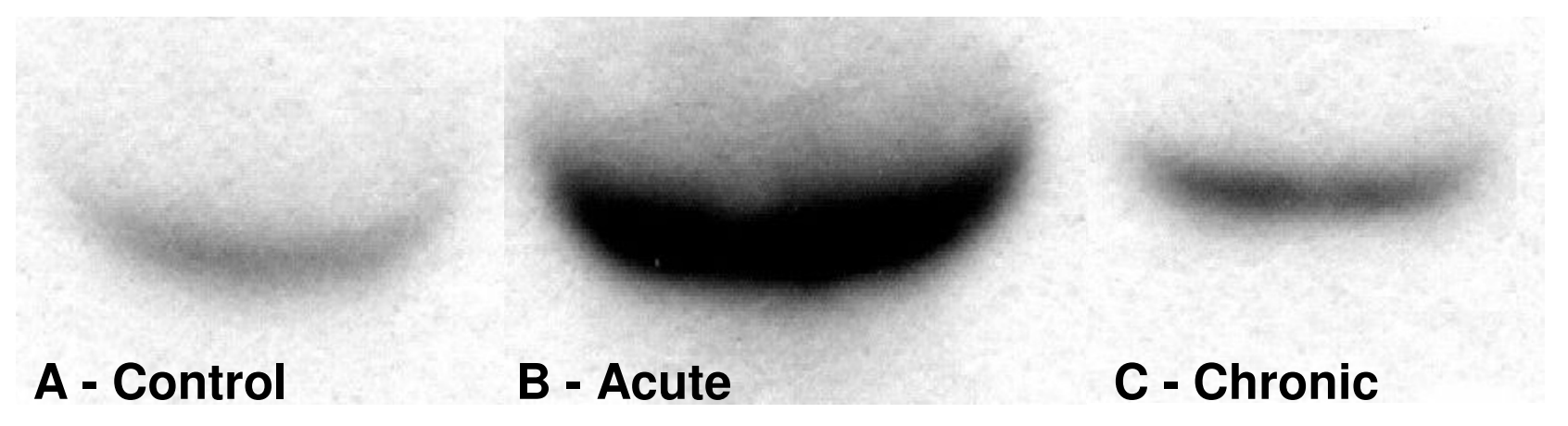

Figure 4

Cox-2 70-kDa band by Western blots. Cox-2 70-kDa band in control nerve (A), acute injured nerve (B) and chronic injured nerve $(\mathrm{C})$. The Cox-2 $70 \mathrm{kDa}$ band was clearly more prominent in the acute nerves.

Quantification of Cox-2-IR in the time course showed significantly $(\mathrm{p}<0.02)$ lower levels in the lesioned superficial dorsal horn of the spinal cord compared to shamoperated at all three time points (Figure 11). Quantification of OX42-IR showed increased significant levels of OX42-IR across the time course $(\mathrm{p}<0.03)$ and across the main three areas in the lesioned side of the spinal cord superficial dorsal horn (Figure 11), deep dorsal horn (data not shown) and ventral horn (data not shown).

\section{Discussion}

Tissue damage generates an inflammatory response resulting in release of inflammatory mediators that in turn causes pain and hyperalgesia. Macrophages, other immunocompetent cells, as well as increased levels of cytokines have been found in injured nerves and DRG $[35,38,39]$. Macrophages have been found to be the predominant source of prostanoid release $[40,41]$. Prostanoids sensitise peripheral nerve terminals, and are also produced and released in the spinal cord following peripheral nerve injury, establishing both peripheral and CNS links between prostaglandin production and hypersensitivity $[10,42]$.

In the present study, the time course of macrophage/ microglia-like cell activation was studied in comparison with Cox-2 levels and EP1 receptor levels in human injured nerves and a rodent model of nerve injury. EP1 receptor levels were reported for the first time in human nerve fibres and DRG, and appeared increased in acutely injured tissues. The greater increase distally of EP1 was a trend, and not statistically significant, and could be the result of increased EP1 in regenerating or spared fibres. The EP1 time course when compared to the previously published time course of Cox-2 [35] showed rapid elevated levels of EP1 receptor in proximal nerves. The previ- ous paper reported both proximal and distal nerve staining, but only proximal nerve stumps were used to compare directly with EP1 immunostaining for the same specimens in this study. In accord with our previous report [35], Cox-2-IR was increased from some weeks after injury, whereas CD68-positive macrophages were increased more acutely - in this study, we have demonstrated, in addition, that the Cox-2-IR increase in macrophages persists over many years in injured human

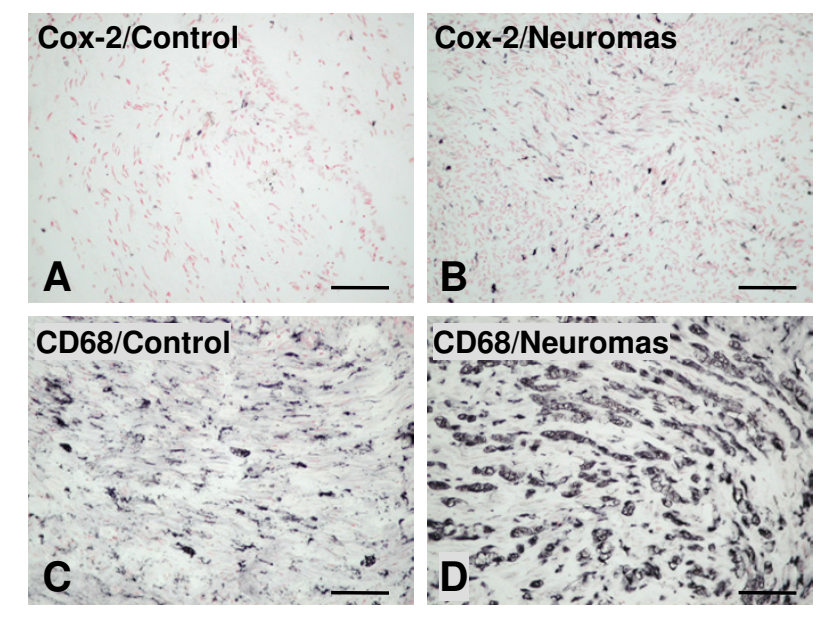

Figure 5

Cox-2 and CD68 immunoreactive cells in uninjured nerves and human neuromas. Very few scattered Cox-2 immunoreactive cells were found in uninjured human nerve tissue (A) compared to human neuromas (B). CD68 immunoreative cells were of similar morphology and distribution as Cox-2 and were observed with greater abundance in injured nerve (D) than in control (C). Magnification bars $=50$ $\mu \mathrm{m}$. 


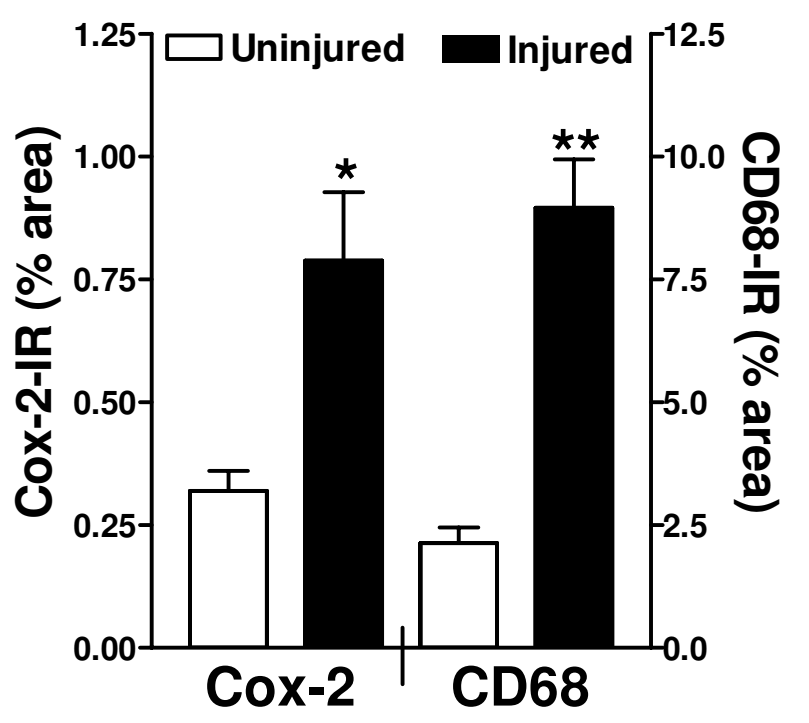

Figure 6

Cox-2-IR and CD68-IR in human painful neuromas.

Cox-2-IR and CD68-IR (in \% area) are significantly increased in injured nerves compared to control nerves. ${ }^{*} p<0.002$; $* *$ $\mathrm{p}<0.000 \mathrm{l}$.

neuromas. After injury nerves show rapid swelling and oedema formation. Due to this swelling, the \% positive areas measured might account for the lower levels of Cox2-IR with image analysis compared to controls - when we analysed our nerves by counting positive cell numbers per area, no significant change (i.e. no decrease) was observed. A $70 \mathrm{kDa}$ Cox-2 band was significantly increased in acute injured human nerve extracts, but not chronic, and are apparently discrepant with immunohistochemical findings - this may reflect the time-points at which limited numbers of nerves were available in sufficient quantities to enable western blotting studies, as only those clustering around the broad peak of Cox-2 increase ( 2 - 8 weeks) would be expected, and showed, significant increase. The nerve samples extracts that constitute the Western blotting "acute" group represented the later stage of the acute phase i.e., 10, 15 and 17 days, and the "chronic" group included 3 out of 5 samples beyond 10 weeks after injury.

In the CCI rat model, numerous OX42-IR macrophage/ microglial-like cells appeared in the injured sciatic nerves, as well as in the superficial dorsal horn of the spinal cord in CCI rats, at 4 days post operation. However, while there was a trend, Cox-2-IR was not significantly increased in nerves. A similar change was also found at 21 days postoperation in CCI nerve tissue in recent different set of animals (data not included); a significant increase of Cox-2IR at 40 days post-injury in CCI nerve was reported by us

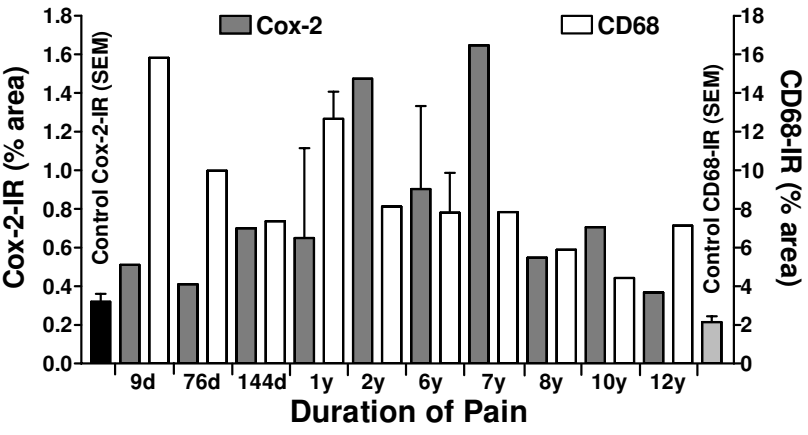

Figure 7

Cox-2-IR and CD68-IR in human neuromas - time course. Rapid increase of CD68 immunoreactive cells was observed, whilst Cox-2-IR was only apparent from 2 to 3 weeks as previously described and remained persistent over many years.

previously [35]. In this study Cox-2 immunoreactivity just failed to reach significance at days 4 and 21 in the CCI rats, possibly because the increase was not as robust as at day 40 after injury, and/or due to a smaller number of animals in the present study. Two cited papers $[43,44]$ showed an upregulation of Cox-2 in CCI and partial nerve ligation nerves at 2 and 4 weeks after injury, also in macrophages, but they counted Cox-2 positive cells per area in one study and a comparison between sham and CCI contralateral sciatic nerve was not assessed [43], whereas we image-analysed \% area of the sections and conducted statistical comparison, which may account for the differences in our studies. When we re-analysed our CCI nerves by counting positive cell numbers per area, a trend for an increase was observed but this still did not achieve statistical significance (data not shown). In another study, when Cox-2 positive cells were compared between ipsiand contralateral sciatic nerve (modified Chung model), not all time points (i.e. 3 days) reached levels of significance [45].

In the CCI rat spinal cord, a significant increase of OX42 immunoreactive macrophage/microglial-like cells was observed over the entire time course (4-30 days) in the lesioned side superficial dorsal horn; however, Cox-2-IR was, surprisingly, found to be decreased at all these time points. Sufficient tissues were not available for Western blotting of Cox-2 in rat spinal cord, but are necessary to substantiate present findings. The underlying mechanisms and significance of this decrease remain hence uncertain; it should be noted that we have previously reported using the same methods that Cox-2 immunoreactive macrophage-like cells in the nerves and in the lesioned superficial dorsal horn of the CCI rats were increased above normal levels at 40 days post operation, 


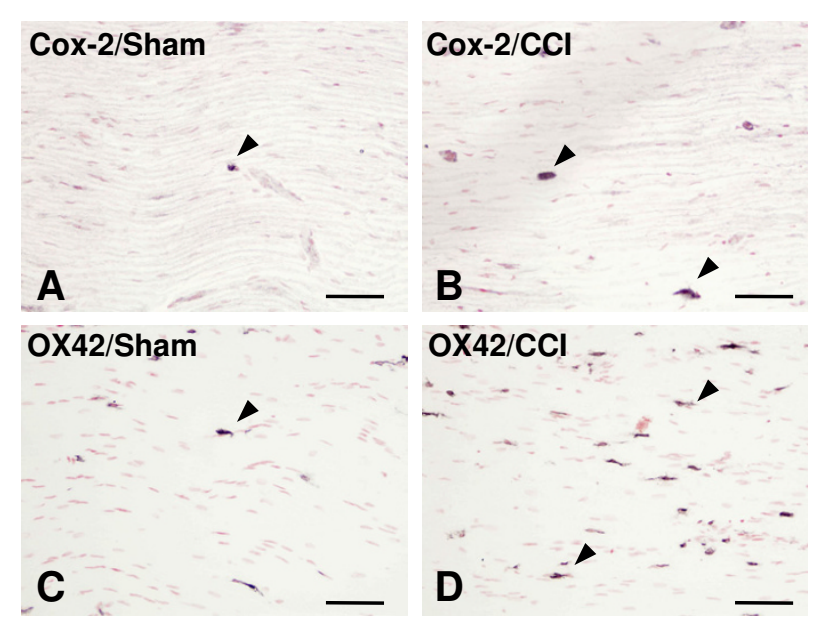

Figure 8

Cox-2 and $0 \times 42$ immunoreactive cells in sham and $\mathrm{CCl}$ rat nerve at 4 days post operation. Very few Cox2 immunoreactive cells (arrowheads) were observed in the left sciatic nerve of sham-operated (A) compared to $\mathrm{CCl}(\mathrm{B})$. Similarly, sham-operated nerves $(C)$ showed much less macrophages in the sciatic nerve than $\mathrm{CCl}$ nerves $(D)$. Scale bars $=50 \mu \mathrm{m}$.

suggesting a delay in the expression of Cox-2 [35]. Structural reorganisation in the spinal cord after peripheral nerve injury [46] could account for the delayed expression of Cox-2 in macrophage/microglial-like cells.

A number of other studies have described Cox-2 changes in different cell types in animal models of nerve injury. Using a modified Chung model, where only L5 was severed $[47,48]$, different stages of Cox-2 expression were observed in the sciatic nerve, with an early or first phase (after 1 day), where Cox-2-IR was co-localised with a Schwann cell marker, followed by a second phase, involving macrophages [45]. In the spared nerve injury (SNI) model [49], a small increase in Cox-2 mRNA protein was demonstrated in the dorsal horn at 24 hours post surgery, returned to sham levels at 72 hours, and was decreased at 7 days [50]. Furthermore, Cox-2-IR was shown by immunohistochemical methods to be only slightly increased in the deeper layers of the L4-L5 dorsal horn of the spinal cord at 10 hours post surgery. In this study pain behaviour in the rats was apparent from 9 days and maintained until 30 days post operation, which suggests that the neuropathic pain behaviour tested was not correlated, at the time-points studied, with significantly increased Cox-2 expression, in accord with the findings of some other investigators [32].

In a rodent partial nerve ligation study, EP1-IR was found near the sciatic nerve ligation site, in nuclei of cells co-

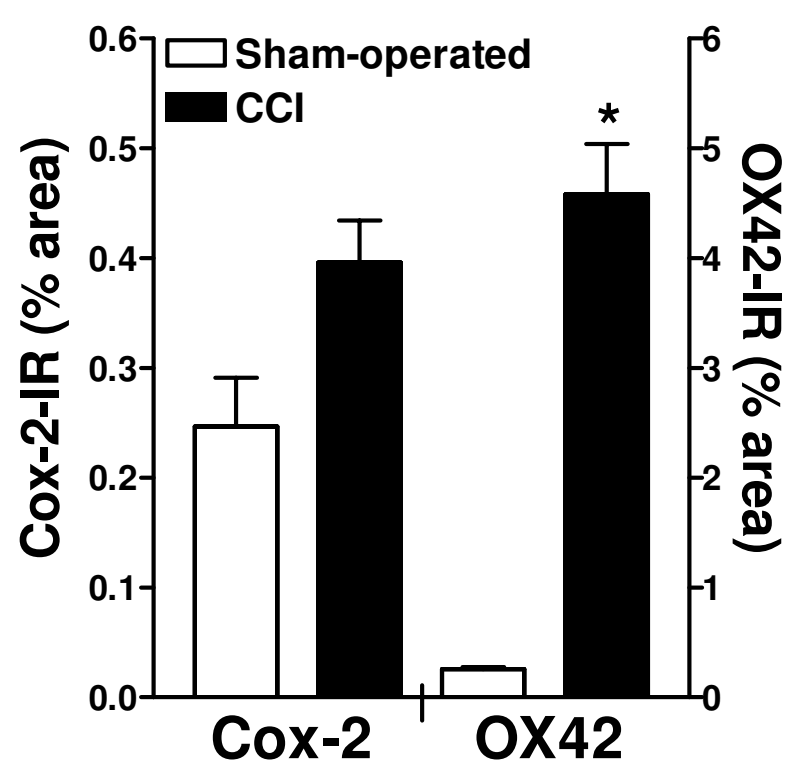

Figure 9

Cox-2-IR and OX42-IR in sham-operated and $\mathrm{CCI}$ lesioned rat nerve at 4 days post-operation. At 4 days post-operation, OX42-IR was significantly increased in lesioned nerves compared to sham-operated nerves whilst Cox-2-IR was not significantly increased. ${ }^{*} p<0.015$.

expressing the macrophage marker ED1 [51]. However, in the present study, we found EP1 receptors to be mainly expressed in axons and cell bodies of human sensory neurones. The regulation of EP1 receptors in injured sensory neurones and inflammatory cells deserves further investigation. The molecular regulators of EP1 expression in DRG neurons are unknown - trauma and initial inflammatory response (shown by rapid increases of CD68-IR) may lead to increased EP1 levels, to which PGs may contribute. Later, Cox-2 expression in macrophages may be involved in the persistence of pain. The time-course of Cox-2 expression also suggests a role in the processes of Wallerian degeneration and regeneration. Further investigations are required, including studies of chronic nonpainful human neuromas, to establish a link between EP1 and Cox-2 levels with pain.

A number of clinical and animal model pharmacological studies suggest that Cox-2 and EP1 are key therapeutic targets in inflammatory and neuropathic pain. The selective Cox-2 inhibitor, GW406381X, was shown to be effective in reducing mechanical allodynia in the CCI rat model, and thermal hyperalgesia in the mouse partial ligation model, both animal models of neuropathic pain [47]. GW406381X was also effective in reducing pain behaviour when given intrathecally and orally to rats with cap- 

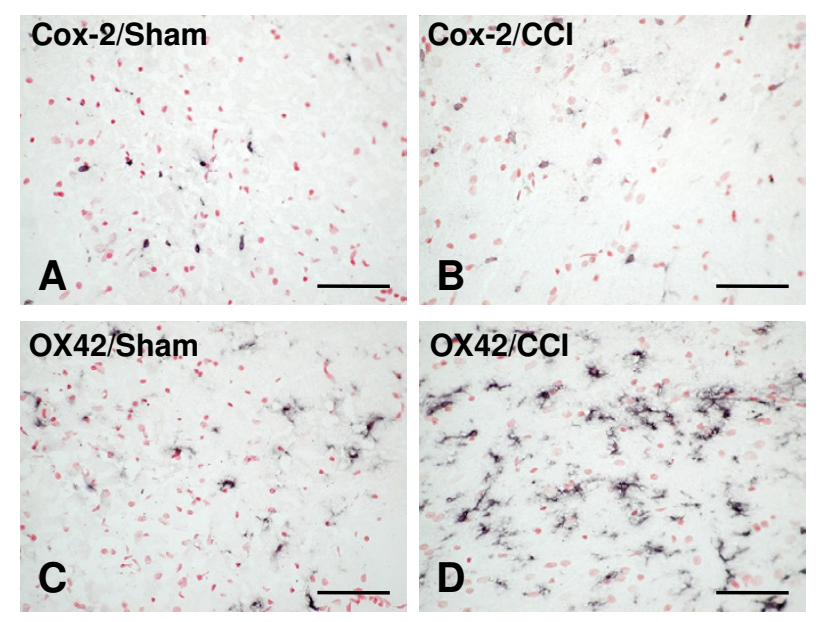

Figure 10

Cox-2 and OX42 immunoreactive cells in the superficial dorsal horn of rat spinal cord (Laminae I-II). At 4 days post-operation, Cox- 2 immunoreactive cells were more abundant in controls (A) compared to $\mathrm{CCl}(\mathrm{B})$, whilst few OX42 immunoreactive cells were seen in the superficial dorsal horn of sham-operated spinal cord (C) compared to $\mathrm{CCl}$ (D). Magnification bars $=50 \mu \mathrm{m}$.

saicin-induced inflammatory pain [52]. The selective Cox2 inhibitor, etodolac, administered orally, reduced heatevoked hyperalgesia in rats with chronic constrictive sciatic nerve injury [53]. Other Cox-2 inhibitors such as celecoxib and rofecoxib, however, are effective in inflammatory pain but do not alter neuropathic pain behaviour. Intraperitoneal injection of Rofecoxib, a selective cox-2 inhibitor, did not prevent the development of allodynia and hyperalgesia in the spared nerve injury model [50].

EP1 antagonists may be effective in neuropathic, inflammatory and incisional pain models. In the CCI model, oral administration of an EP1 antagonist from 8 to 14 days post-operation effectively reduced CCI-induced mechanical hyperalgesia and allodynia [20]. In another animal model of neuropathic pain (partial ligation of the sciatic nerve), mechanical and thermal hyperalgesia was reversed with a EP1 receptor antagonist (SC-19220) [54]. EP1 receptor antagonists reduced the response to formalin-induced inflammation $[55,56]$. Spinal application of EP agonists in an inflammatory rat knee joint model demonstrated that EP1, EP2 and EP4 agonists all generated spinal hyperexcitability similar to $\mathrm{PGE}_{2}$ [57]. In a rat model of postoperative pain administration of an EP1 antagonist (ONO-8711) generated analgesic effects on mechanical evoked pain $[58,59]$. Similar inhibitory effects on mechanical hyperalgesia with the same EP1 antagonist were shown in a carrageenan-induced inflammatory model [60]. The second phase, but not the first phase, of

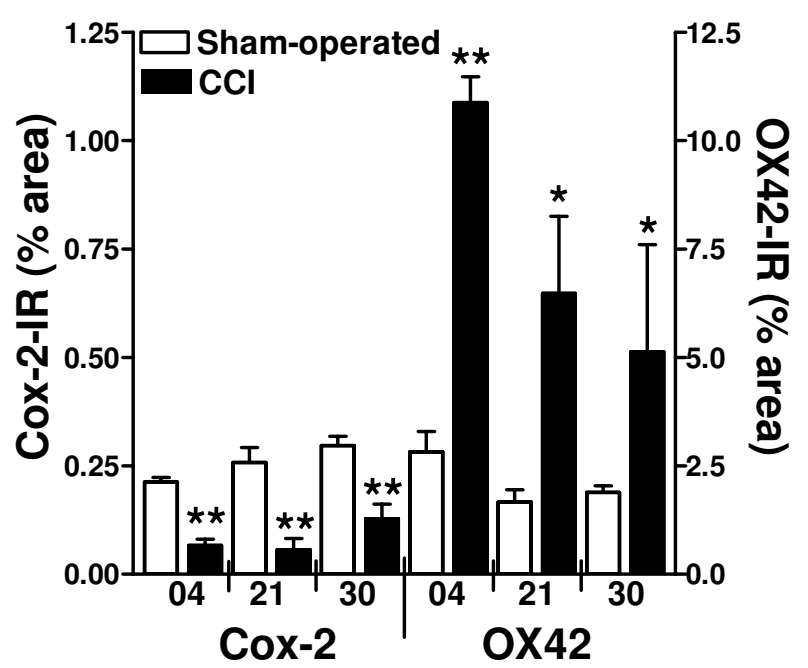

Figure I I

Cox -2-IR and OX42-IR in dorsal horn of rat spinal cord (Laminae I-II). Cox-2-IR levels were significantly lower in the lesioned superficial dorsal horn of the rat spinal cord compared to the sham-operated spinal cord at 4, 2 I and 30 days post operation. OX42-IR was significantly increased in the lesioned superficial dorsal horn of the rat spinal cord across the time course. ${ }^{*} p<0.03$; ${ }^{* *} p<0.02$.

formalin-induced flinching behaviour in the paw was effectively inhibited by spinally administered EP1 receptor antagonists (SC-51089 and SC-51234A) [56]. Importantly, the involvement of PGE2 in sensitisation via the EP1 receptor has also been shown in human oesophageal pain hypersensitivity, with the successful use of an EP1 antagonist [24].

\section{Conclusion}

In this study, we report that a rapid increase of EP1 receptor levels in injured human sensory neurones preceded Cox-2 expression in infiltrating macrophages. Chronic painful human neuromas showed persistence of EP1-IR in nerve fibres and increased Cox-2-IR macrophages. EP1 antagonists may show therapeutic effects in acute and chronic neuropathic pain, in addition to inflammatory pain.

\section{Competing interests}

The author(s) declare that they have no competing interests.

\section{Authors' contributions}

Pascal F Durrenberger, Paul Facer and Maria Casula performed the immunostaining studies and helped write the manuscript. Roy A Gray, Sue D Collins, Sharon Bingham and Alex W Wilson prepared the CCI model and collected 
tissues. Iain P Chessell and Nicola C Day helped with the design of the studies, and the screening and selection of the antibodies. David Elliot and Rolfe Birch provided the human nerve specimens. Praveen Anand designed the study, helped collect the control nerve tissues, and helped write the manuscript.

\section{Acknowledgements}

This work was supported by the Medical Research Council UK and GlaxoSmithKline. We would like to thank The Chelmsford Medical Education and Research Trust (CMERT) for their contribution in this project by providing us with some of the human tissue specimens.

\section{References}

I. Ma W, Du W, Eisenach JC: Role for both spinal cord COX-I and COX-2 in maintenance of mechanical hypersensitivity following peripheral nerve injury. Brain Res 2002, 937:94-99.

2. Seybold VS, jia YP, Abrahams LG: Cyclo-oxygenase-2 contributes to central sensitization in rats with peripheral inflammation. Pain 2003, 105:47-55.

3. Sirois J, Simmons DL, Richards JS: Hormonal regulation of messenger ribonucleic acid encoding a novel isoform of prostaglandin endoperoxide $\mathbf{H}$ synthase in rat preovulatory follicles. Induction in vivo and in vitro. J Biol Chem 1992, 267: II586-II592.

4. Vane JR, Bakhle YS, Botting RM: Cyclooxygenases I and 2. Annu Rev Pharmacol Toxicol 1998, 38:97-I 20.

5. O'Neill GP, Ford-Hutchinson AW: Expression of mRNA for cyclooxygenase-I and cyclooxygenase- 2 in human tissues. FEBS Lett 1993, 330:156-160.

6. Harris RC, McKanna JA, Akai Y, Jacobson HR, Dubois RN, Breyer MD: Cyclooxygenase- 2 is associated with the macula densa of rat kidney and increases with salt restriction. J Clin Invest 1994, 94:2504-2510

7. Bauer MK, Lieb K, Schulze-Osthoff K, Berger M, Gebicke-Haerter PJ, Bauer J, Fiebich BL: Expression and regulation of cyclooxygenase-2 in rat microglia. Eur J Biochem I997, 243:726-73I.

8. Minghetti L, Nicolini A, Polazzi E, Greco A, Perretti M, Parente L, Levi G: Down-regulation of microglial cyclo-oxygenase-2 and inducible nitric oxide synthase expression by lipocortin $\mathrm{I}$. $\mathrm{Br}$ J Pharmacol 1999, I 26:1307-1314.

9. Hoffmann C: COX-2 in brain and spinal cord implications for therapeutic use. Curr Med Chem 2000, 7:1 II3-III20.

10. Yaksh TL, Dirig DM, Conway CM, Svensson C, Luo ZD, Isakson PC: The acute antihyperalgesic action of nonsteroidal, antiinflammatory drugs and release of spinal prostaglandin E2 is mediated by the inhibition of constitutive spinal cyclooxygenase-2 (COX-2) but not COX-I. J Neurosci 200I, 2I:5847-5853.

II. Bley KR, Hunter JC, Eglen RM, Smith JA: The role of IP prostanoid receptors in inflammatory pain. Trends Pharmacol Sci 1998, 19:141-147.

12. Narumiya S, Sugimoto Y, Ushikubi F: Prostanoid receptors: structures, properties, and functions. Physiol Rev 1999, 79: I I 93-I 226.

13. Narumiya S, FitzGerald GA: Genetic and pharmacological analysis of prostanoid receptor function. J Clin Invest 200I, 108:25-30

14. Samad TA, Sapirstein A, Woolf CJ: Prostanoids and pain: unraveling mechanisms and revealing therapeutic targets. Trends Mol Med 2002, 8:390-396.

15. Breyer RM, Bagdassarian CK, Myers SA, Breyer MD: Prostanoid receptors: subtypes and signaling. Annu Rev Pharmacol Toxicol 200I, 4I:66I-690.

16. Asboth G, Phaneuf S, Europe-Finner GN, Toth M, Bernal AL: Prostaglandin E2 activates phospholipase $C$ and elevates intracellular calcium in cultured myometrial cells: involvement of EPI and EP3 receptor subtypes. Endocrinology 1996, | 37:2572-2579.

17. Vanegas H, Schaible HG: Prostaglandins and cyclooxygenases [correction of cycloxygenases] in the spinal cord. Prog Neurobiol 200I, 64:327-363.

18. Stock JL, Shinjo K, Burkhardt J, Roach M, Taniguchi K, Ishikawa T, Kim HS, Flannery PJ, Coffman TM, McNeish JD, Audoly LP: The prostag- landin E2 EP I receptor mediates pain perception and regulates blood pressure. J Clin Invest 200I, 107:325-33I.

19. Kobayashi T, Narumiya S: Function of prostanoid receptors: studies on knockout mice. Prostaglandins Other Lipid Mediat 2002, 68-69:557-573.

20. Kawahara H, Sakamoto A, Takeda S, Onodera H, Imaki J, Ogawa R: A prostaglandin E2 receptor subtype EPI receptor antagonist (ONO-87II) reduces hyperalgesia, allodynia, and c-fos gene expression in rats with chronic nerve constriction. Anesth Analg 2001, 93:1012-1017.

21. Hasumoto K, Sugimoto Y, Gotoh M, Segi E, Yamasaki A, Yamaguchi M, Honda H, Hirai H, Negishi M, Kakizuka A, Ichikawa A: Characterization of the mouse prostaglandin $F$ receptor gene: a transgenic mouse study of a regulatory region that controls its expression in the stomach and kidney but not in the ovary. Genes Cells 1997, 2:57I-580.

22. Oida $H$, Namba $T$, Sugimoto $Y$, Ushikubi $F$, Ohishi $H$, Ichikawa $A$, Narumiya S: In situ hybridization studies of prostacyclin receptor mRNA expression in various mouse organs. $\mathrm{Br} J$ Pharmacol 1995, II 6:2828-2837.

23. Donaldson LF, Humphrey PS, Oldfield S, Giblett S, Grubb BD: Expression and regulation of prostaglandin $E$ receptor subtype mRNAs in rat sensory ganglia and spinal cord in response to peripheral inflammation. Prostaglandins Other Lipid Mediat 2001, 63:109-122

24. Sarkar S, Hobson AR, Hughes A, Growcott J, Woolf C], Thompson DG, Aziz Q: The prostaglandin E2 receptor-I (EP-I) mediates acid-induced visceral pain hypersensitivity in humans. Gastroenterology 2003, 124:18-25.

25. Kreutzberg GW: Microglia: a sensor for pathological events in the CNS. Trends Neurosci 1996, 19:3 12-318.

26. Watkins LR, Milligan ED, Maier SF: Glial activation: a driving force for pathological pain. Trends Neurosci 200I, 24:450-455.

27. Scholz J, Woolf CJ: Can we conquer pain? Nat Neurosci 2002, 5 Suppl: $1062-1067$.

28. Shu XQ, Mendell LM: Neurotrophins and hyperalgesia. Proc Natl Acad Sci U S A 1999, 96:7693-7696.

29. Woolf CJ, Costigan M: Transcriptional and posttranslational plasticity and the generation of inflammatory pain. Proc Natl Acad Sci U S A 1999, 96:7723-7730.

30. Watkins LR, Maier SF: Beyond neurons: evidence that immune and glial cells contribute to pathological pain states. Physiol $\operatorname{Rev} 2002,82: 981-1011$.

31. Sommer C, Kress M: Recent findings on how proinflammatory cytokines cause pain: peripheral mechanisms in inflammatory and neuropathic hyperalgesia. Neurosci Lett 2004, 36I:184-187.

32. Colburn RW, DeLeo JA, Rickman AJ, Yeager MP, Kwon P, Hickey WF: Dissociation of microglial activation and neuropathic pain behaviors following peripheral nerve injury in the rat. Neuroimmunol 1997, 79:163-175.

33. Randall LO, Selitto JJ: A method for measurement of analgesic activity on inflamed tissue. Arch Int Pharmacodyn Ther 1957, I I I:409-4I9.

34. Kelly PM, Bliss E, Morton JA, Burns J, McGee JO: Monoclonal antibody EBM/II: high cellular specificity for human macrophages. J Clin Pathol 1988, 41:5 10-5 I5.

35. Durrenberger PF, Facer P, Gray RA, Chessell IP, Naylor A, Bountra C, Banati RB, Birch R, Anand P: Cyclooxygenase-2 (Cox-2) in injured human nerve and a rat model of nerve injury. J Peripher Nerv Syst 2004, 9:15-25.

36. Shu SY, Ju G, Fan LZ: The glucose oxidase-DAB-nickel method in peroxidase histochemistry of the nervous system. Neurosci Lett |988, 85:169-17|.

37. Yiangou $Y$, Facer $P$, Baecker PA, Ford AP, Knowles $\mathrm{CH}$, Chan $\mathrm{CL}$, Williams NS, Anand P: ATP-gated ion channel P2X(3) is increased in human inflammatory bowel disease. Neurogastroenterol Motil 200I, 13:365-369.

38. Wagner R, Janjigian M, Myers RR: Anti-inflammatory interleukin10 therapy in $\mathrm{CCl}$ neuropathy decreases thermal hyperalgesia, macrophage recruitment, and endoneurial TNF-alpha expression. Pain 1998, 74:35-42.

39. Kleinschnitz C, Brinkhoff J, Zelenka M, Sommer C, Stoll G: The extent of cytokine induction in peripheral nerve lesions depends on the mode of injury and NMDA receptor signaling. J Neuroimmunol 2004, 149:77-83. 
40. Bonney RJ, Naruns P, Davies P, Humes JL: Antigen-antibody complexes stimulate the synthesis and release of prostaglandins by mouse peritoneal macrophages. Prostaglandins 1979, | 8:605-616.

4I. Karck U, Reister F, Schafer W, Zahradnik HP, Breckwoldt M: PGE2 and PGF2 alpha release by human peritoneal macrophages in endometriosis. Prostaglandins 1996, $51: 49-60$.

42. Dirig DM, Yaksh TL: Spinal synthesis and release of prostanoids after peripheral injury and inflammation. Adv Exp Med Biol 1999, 469:401-408.

43. Ma W, Eisenach JC: Cyclooxygenase $\mathbf{2}$ in infiltrating inflammatory cells in injured nerve is universally up-regulated following various types of peripheral nerve injury. Neuroscience 2003, 1 21:69|-704.

44. Ma W, Eisenach JC: Morphological and pharmacological evidence for the role of peripheral prostaglandins in the pathogenesis of neuropathic pain. Eur J Neurosci 2002, 15:1037-1047.

45. Takahashi M, Kawaguchi M, Shimada K, Konishi N, Furuya H, Nakashima T: Cyclooxygenase-2 expression in Schwann cells and macrophages in the sciatic nerve after single spinal nerve injury in rats. Neurosci Lett 2004, 363:203-206.

46. Woolf CJ, Shortland P, Reynolds M, Ridings J, Doubell T, Coggeshall RE: Reorganization of central terminals of myelinated primary afferents in the rat dorsal horn following peripheral axotomy. J Comp Neurol 1995, 360: 121-134.

47. Kim SH, Chung JM: An experimental model for peripheral neuropathy produced by segmental spinal nerve ligation in the rat. Pain 1992, 50:355-363.

48. Li Y, Dorsi MJ, Meyer RA, Belzberg AJ: Mechanical hyperalgesia after an $L 5$ spinal nerve lesion in the rat is not dependent on input from injured nerve fibers. Pain 2000, 85:493-502.

49. Decosterd I, Woolf C]: Spared nerve injury: an animal model of persistent peripheral neuropathic pain. Pain 2000, 87:। $149-158$.

50. Broom DC, Samad TA, Kohno T, Tegeder I, Geisslinger G, Woolf C]: Cyclooxygenase 2 expression in the spared nerve injury model of neuropathic pain. Neuroscience 2004, 1 24:89|-900.

5I. Ma W, Eisenach JC: Four PGE2 EP receptors are up-regulated in injured nerve following partial sciatic nerve ligation. Exp Neurol 2003, 183:58I-592.

52. Bingham S, Beswick PJ, Bountra C, Brown T, Campbell IB, Chessell IP, Clayton N, Collins SD, Davey PT, Goodland H, Gray N, Haslam C, Hatcher JP, Hunter AJ, Lucas F, Murkitt G, Naylor A, Pickup E, Sargent B, Summerfield SG, Stevens A, Stratton SC, Wiseman J: The cyclooxygenase 2 inhibitor, GW40638 I is effective in animal models of neuropathic pain and central sensitisation. I Pharmacol Exp Ther 2004

53. Suyama H, Kawamoto M, Gaus S, Yuge O: Effect of etodolac, a COX-2 inhibitor, on neuropathic pain in a rat model. Brain Res 2004, 1010:144-150.

54. Syriatowicz JP, Hu D, Walker JS, Tracey DJ: Hyperalgesia due to nerve injury: role of prostaglandins. Neuroscience 1999, 94:587-594.

55. Malmberg AB, Yaksh TL: Antinociceptive actions of spinal nonsteroidal anti-inflammatory agents on the formalin test in the rat. J Pharmacol Exp Ther 1992, 263:136-146.

56. Malmberg AB, Rafferty MF, Yaksh TL: Antinociceptive effect of spinally delivered prostaglandin $E$ receptor antagonists in the formalin test on the rat. Neurosci Lett 1994, 173:193-196.

57. Bar KJ, Natura G, Telleria-Diaz A, Teschner P, Vogel R, Vasquez E, Schaible HG, Ebersberger A: Changes in the effect of spinal prostaglandin E2 during inflammation: prostaglandin E (EPIEP4) receptors in spinal nociceptive processing of input from the normal or inflamed knee joint. J Neurosci 2004, 24:642-65I.

58. Omote K, Yamamoto H, Kawamata T, Nakayama $Y$, Namiki A: The effects of intrathecal administration of an antagonist for prostaglandin $E$ receptor subtype $E P(I)$ on mechanical and thermal hyperalgesia in a rat model of postoperative pain. Anesth Analg 2002, 95: 1708-12, table of contents.

59. Omote K, Kawamata T, Nakayama Y, Kawamata M, Hazama K, Namiki $A$ : The effects of peripheral administration of a novel selective antagonist for prostaglandin $E$ receptor subtype EP(I), ONO-87II, in a rat model of postoperative pain. Anesth Analg 200I, 92:233-238.

60. Nakayama Y, Omote K, Namiki A: Role of prostaglandin receptor EPI in the spinal dorsal horn in carrageenan-induced inflammatory pain. Anesthesiology 2002, 97:| 254-I 262.

\section{Pre-publication history}

The pre-publication history for this paper can be accessed here:

http://www.biomedcentral.com/1471-2377/6/1/prepub
Publish with Bio Med Central and every scientist can read your work free of charge

"BioMed Central will be the most significant development for disseminating the results of biomedical research in our lifetime. "

Sir Paul Nurse, Cancer Research UK

Your research papers will be:

- available free of charge to the entire biomedical community

- peer reviewed and published immediately upon acceptance

- cited in PubMed and archived on PubMed Central

- yours - you keep the copyright

Submit your manuscript here:

http://www.biomedcentral.com/info/publishing_adv.asp 